\title{
Challenges towards Economic Fuel Generation from Renewable Electricity: The Need for Efficient Electro-Catalysis
}

\author{
Florian Le Formal, Wiktor S. Bourée, Mathieu S. Prévot, and Kevin Sivula*
}

\begin{abstract}
Utilizing renewable sources of energy is very attractive to provide the growing population on earth in the future but demands the development of efficient storage to mitigate their intermittent nature. Chemical storage, with energy stored in the bonds of chemical compounds such as hydrogen or carbon-containing molecules, is promising as these energy vectors can be reserved and transported easily. In this review, we aim to present the advantages and drawbacks of the main water electrolysis technologies available today: alkaline and PEM electrolysis. The choice of electrode materials for utilization in very basic and very acid conditions is discussed, with specific focus on anodes for the oxygen evolution reaction, considered as the most demanding and energy consuming reaction in an electrolyzer. State-of-the-art performance of materials academically developed for two alternative technologies: electrolysis in neutral or seawater, and the direct electrochemical conversion from solar to hydrogen are also introduced.
\end{abstract}

Keywords: Electrochemical water splitting · Energy storage $\cdot$ Hydrogen $\cdot$ Oxygen evolution reaction

\section{Introduction}

The current global energy supply system, mainly based on fossil fuels and nuclear power, will change dramatically in the next decades. The accelerated depletion of non-renewable energy resources and ecological consequences associated to their use are a major concern for both policy makers and the general population. In a recent review of different possible scenarios for the Swiss electricity system until the year 2050, renewable sources of energy are forecasted to be deployed on a large scale after a transition period based on natural gas-powered generation. ${ }^{[1]}$ In addition to reducing the climate impact from fossil fuels, enhanced utilization of renewable energy is expected to help bring electricity to the 1.6 billion people in the world currently without access to energy, meeting the energy demand of a growing population and ensuring stable and secure energy access for all nations. ${ }^{[2]}$

\footnotetext{
${ }^{\star}$ Correspondence: Prof. K. Sivula

École Polytechnique Fédérale de Lausanne (EPFL) Institute of Chemistry and Chemical Engineering $\mathrm{CH}$ H4 565, Station 6

$\mathrm{CH}-1015$ Lausanne

E-mail: kevin.sivula@epfl.ch
}

Globally, renewable energy can be extracted from a few key available resources: hydroelectric (0.5 terawatts (TW), available at maximum), from all tides \& ocean currents (2 TW), geothermal integrated over all of the land area (12 TW), globally extractable wind power (2-4 TW), and solar energy illuminating the earth $(120,000$ TW). [3] In total, the maximum energy that can be converted from these sustainable sources substantially exceeds the energy consumed by humans on earth today, ( $c a$. 600 EJ per annum corresponding to an average consumption rate of $17 \mathrm{TW}$ ), and also the predicted usage rate for 2050 and 2100 (40.3 and 48.8 TW respectively). ${ }^{[4]}$ Additionally, it is also striking that the conversion of only $0.05 \%$ of the solar energy (or $0.5 \%$ considering solar cells with $10 \%$ conversion efficiency) would be sufficient to secure the energy demand for the next century.

However, the major limitations towards expanded use of renewable energy sources in the global energy portfolio are currently their availability and intermittency. ${ }^{[5,6]}$ These drawbacks can be overcome through the conversion and storage of renewable energy into a stable but accessible form allowing energy use when needed.[6] Energy storage is especially needed to accommodate the disaccord between the times of energy peak production and of peak consumption as well as transporting energy from where it is harvested to where it is used.[1] Fig. 1 shows an example of the discrepancy between the load on the electric network and the energy generated from renewable sources (wind, solar and wave) in the Pacific Northwest of the U.S. ${ }^{[7]}$ All data, originating from both real and simulated sources, show the daily average for each category through the year 2008 (pu: penetration units defined as the ratio of the peak load to the peak generation within the year). The load, solar, and wave data sets exhibit both diurnal and seasonal variability, while the wind generation appears to be less seasonally correlated.

Wind and wave data also show a large disparity in power generated each day, in contrast to the load. Notably the largest load values are in the end and beginning of the year (the winter months), which is the same time when solar output is negligible. This set of data demonstrates the necessity of storing the energy from renewable sources on a short timescale (i.e. daily to accommodate wind / wave variability and night / day divergence in generation and usage) and on a longer period — on the time scale of a year for solar or wave energy, for example.

Chemical storage, i.e. storing energy in the bonds of molecules such as hydrogen or simple carbon-based compounds (e.g. methane, methanol or formic acid), is particularly attractive as this method does not exhibit limitation to the storage time. Indeed there are potentially very few losses during the storing period (depending on the stability of the compounds) compared to electrochemical energy storage (e.g. in Li-ion batteries). Moreover, $\mathrm{H}_{2}$ or carbonbased fuels could be integrated to existing distribution systems for fossil gas or oil.. ${ }^{[8]}$

One potential way to form these chemical energy storage vectors from electricity 


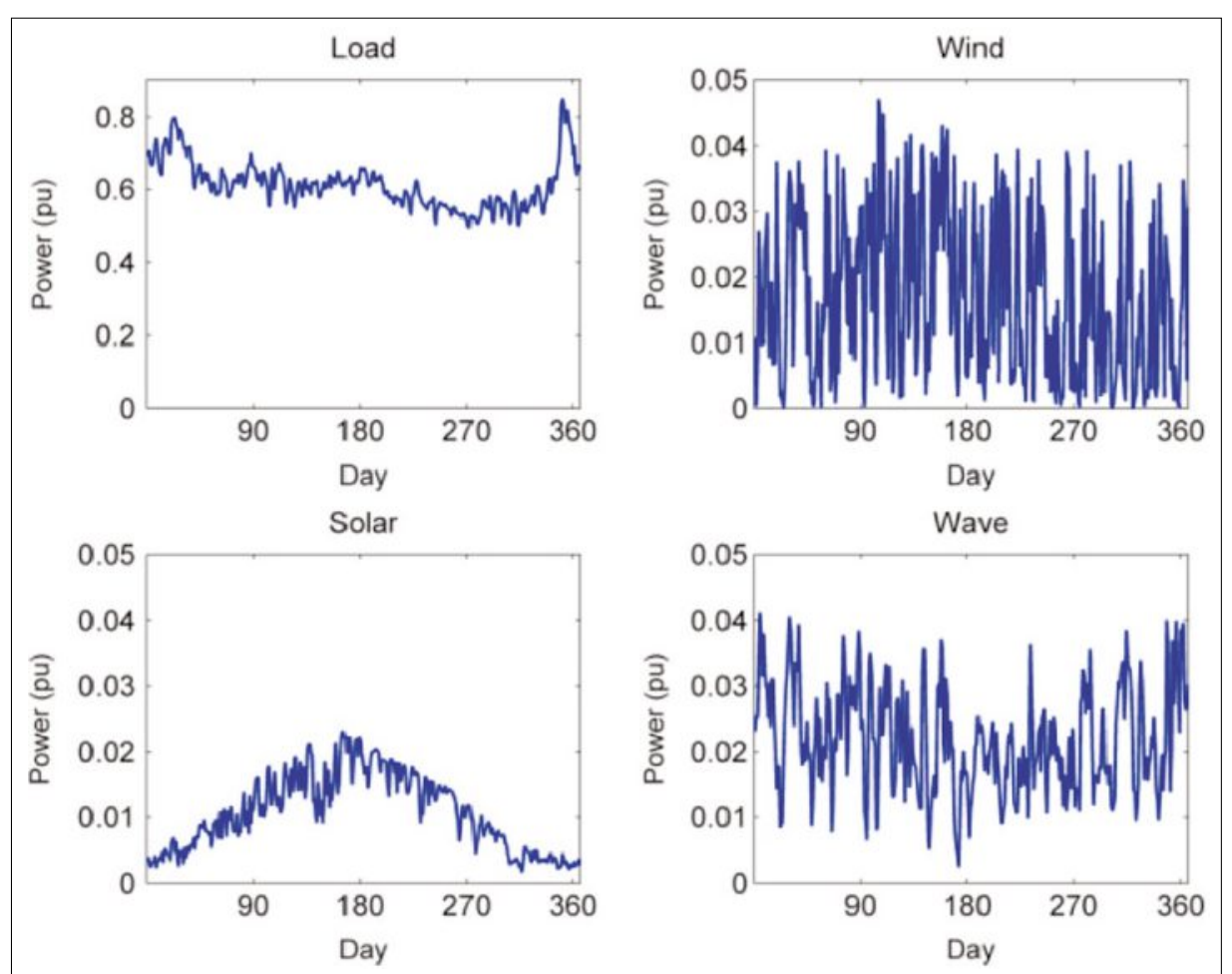

Fig. 1. Plots for load (top left), wind (top right), solar (bottom left) and wave (bottom right) power measured or simulated in the North Pacific region (U.S.) through the year 2008. (C) 2011 IEEE. Reprinted, with permission, from Sustainable Energy, IEEE Trans. 2011, 2, 321-328.

is to use an electrochemical cell, where a difference in electric potential (voltage) drives a non-spontaneous reaction. In an electrochemical cell the overall reaction is composed of two half-reactions that occur at distinct sites in the cell: the oxidation reaction at the anode and the reduction reaction at the cathode. In order to produce hydrogen, water - the most abundant source of hydrogen on earth - can be electrochemically reduced at the cathode to make $\mathrm{H}_{2}$. Carbon-based fuels can be formed either by directly reducing $\mathrm{CO}_{2}$ at the cathode or indirectly: by using the hydrogen produced in a water electrolysis cell to drive the reverse water gas shift and Fischer-Tropsch processes separately (to produce $\mathrm{CO}$ from $\mathrm{CO}_{2}$ and subsequently reduce it to form $\mathrm{C}_{\mathrm{n}} \mathrm{H}_{(2 \mathrm{n}+2)}$ compounds with hydrogen). In both cases, the corresponding oxidation reaction is most conveniently water oxidation to produce molecular oxygen at the anode. Indeed, due to the abundance of water and its relatively low free Gibbs energy of dissociation $(237.1 \mathrm{~kJ}$ corresponding to an oxidation potential of $1.229 \mathrm{~V}$ at standard conditions according to Nernst equation), water is the most obvious candidate to provide electrons (i.e. to be oxidized) in the electrochemical cell.

While $\mathrm{H}_{2}$ and $\mathrm{O}_{2}$ production via water splitting is an attractive route for storing renewable energy, a hydrogen-based energy economy has been sluggish to be adopted by society as, in part, the price of the hydrogen produced via renewable electricity electrolysis is 5-10 times greater than
$\mathrm{H}_{2}$ produced from fossil fuels. Thus there is a strong motivation to optimize water splitting technology to reduce the price. In this mini-review, we focus on the electrochemical production of hydrogen via water splitting, with particular attention to the development of the oxidation electrode, where the majority of the losses remain at present. We will present first the two main systems already well developed for $\mathrm{H}_{2}$ production: alkaline and PEM electrolyzers, and discuss their limitations and challenges toward reducing the price. Next we discuss the prospect to conduct water electrolysis in neutral $\mathrm{pH}$ and seawater, as this approach is industrially very attractive. In the last section, we will give a brief overview of the direct electrochemical solar-to-hydrogen conversion systems.

\section{Overview of Commercial Electrolyzers and Electrode Characterization}

Three electrolyzer technologies are currently well-developed and available commercially: conventional alkaline electrolyzers (with liquid electrolyte), Proton Exchange Membrane (PEM) electrolyzers and most recently anion exchange membrane (AEM or alkaline Polymer Exchange Membrane) electrolyzers have emerged. The latter technology will not be discussed in detail as it is still under development and limited to very specific applications. [9]

Both alkaline and PEM electrolysis systems have comparable efficiencies and operate at similar temperature $\left(50-100{ }^{\circ} \mathrm{C}\right)$ and pressure ( $<30$ bars). ${ }^{[9,10]}$ Alkaline water electrolysis is widely recognized as the most mature and the most widespread technology. It offers the possibility to use large area electrodes but its large-scale deployment is restricted by the maximum current density and the purity of the hydrogen generated (99.5-99.9\%). ${ }^{[11,12]}$ PEM electrolyzers have a slight advantage in terms of gas purity ( $>99.99 \%$ ), efficiency and produced-hydrogen cost but suffer from poor stability. ${ }^{[9,13]}$ The operating principles of an alkaline electrolyzer and a PEM electrolyzer are illustrated in Fig. 2a and $2 \mathrm{~b}$ respectively.

The main differences between the two types of electrolyzer are the electrolyte and the membrane separating the two electrodes. While in an alkaline electrolysis cell, the two electrodes are separated by a gas-tight diaphragm submerged in a liquid electrolyte, a solid proton-conducting polymer membrane is used to isolate the oppositely charged electrodes in a PEM cell (typically Nafion ${ }^{\mathrm{TM}}$ ). The higher permeability to gas of the diaphragm as compared to a PEM reduces the efficiency of the alkaline system due to oxygen diffusion on the cathodic side. ${ }^{[12]}$

The electrolyte used for a alkaline electrolyzer is highly basic, usually a 20-40 wt\% aqueous solution of potassium hydroxide $(\mathrm{KOH})$, which is preferred over sodium hydroxide $(\mathrm{NaOH})$ due to its higher ionic conductivity. In contrast, in a PEM electrolyzer, high purity water $\left(<1 \mu \mathrm{S} \mathrm{cm}^{-1}\right)$ is required for the cell to operate at high efficiency, increasing the cost of this technology. ${ }^{[11]}$ The difference in the employed $\mathrm{pH}$ results in different chemical processes occurring on the electrodes.

In the alkaline system, water is reduced at the cathode according to Eqn. (1), evolving hydrogen and generating hydroxyl anions. These hydroxyl groups migrate through the ion-permeable diaphragm to reach the anode side, where they are oxidized (Eqn. (2)) to generate oxygen and extract the four electrons required for the reduction.

$$
\begin{aligned}
& \text { Alkaline / Cathode: } \\
& 4 \mathrm{H}_{2} \mathrm{O}+4 \mathrm{e}^{-} \rightarrow 2 \mathrm{H}_{2(\mathrm{~g})}+4 \mathrm{OH}^{-}
\end{aligned}
$$

$$
\begin{aligned}
& \text { Alkaline / Anode: } \\
& 4 \mathrm{OH}^{-} \rightarrow \mathrm{O}_{2(\mathrm{~g})}+2 \mathrm{H}_{2} \mathrm{O}+4 \mathrm{e}^{-}
\end{aligned}
$$

In the PEM system, water is oxidized at the anode, generating four protons and transferring four electrons to the external electric circuit. Protons are transferred to the cathodic side through the proton exchange membrane and react with the four 
a) Alkaline electrolyzer

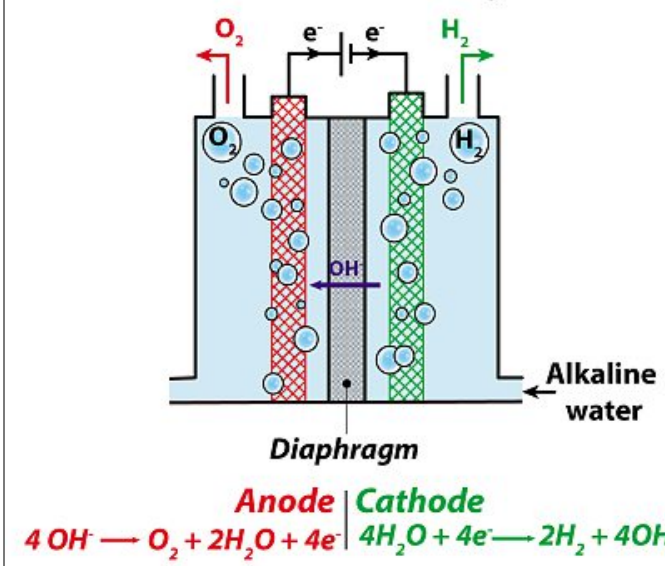

b) PEM electrolyzer

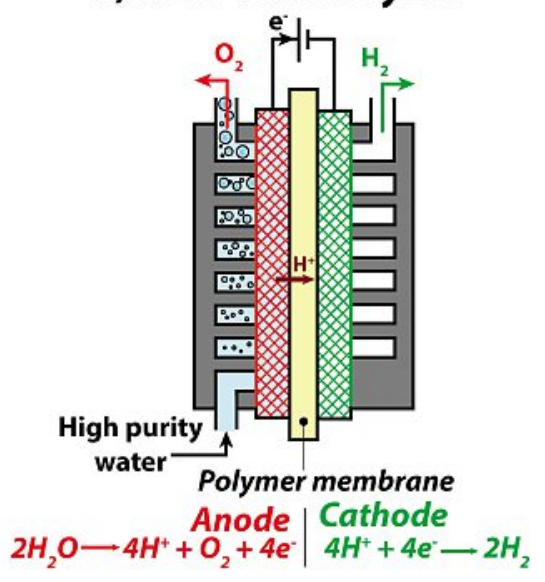

c) Electrode Characterization

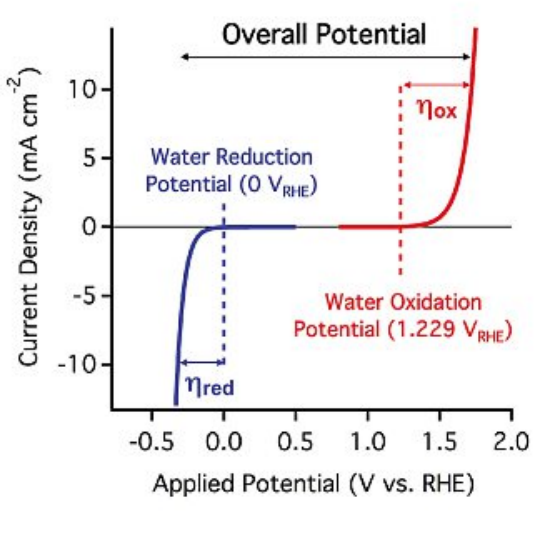

Fig. 2. Scheme of conventional electrolyzers: a) Alkaline and b) PEM based, which operate in basic and acidic pH respectively. c) Typical electrochemical characterization, shown as the current density running through the electrode versus the applied potential against the reversible hydrogen reference electrode (RHE), for an electrode working as an anode (red) and a cathode (blue).

electrons from the electric circuit, resulting in the formation of hydrogen gas. These reactions are summarized in Eqn. (3) and Eqn. (4):

$$
\begin{aligned}
& \text { PEM / Cathode: } \\
& 4 \mathrm{H}^{+}+4 \mathrm{e}^{-} \rightarrow 2 \mathrm{H}_{2(\mathrm{~g})}
\end{aligned}
$$

PEM / Anode:

$$
2 \mathrm{H}_{2} \mathrm{O} \rightarrow \mathrm{O}_{2(\mathrm{~g})}+4 \mathrm{H}^{+}+4 \mathrm{e}^{-}
$$

The same overall reaction occurs in both systems, which corresponds to the water dissociation reaction:

$$
2 \mathrm{H}_{2} \mathrm{O} \rightarrow \mathrm{O}_{2}+2 \mathrm{H}_{2(\mathrm{~g})}
$$

Typical electrochemical characterization (shown in Fig. 2c) of water splitting anodes (red) and cathodes (blue) is usually performed in a three-electrode (potentiostatic) setup, to probe specifically one of the electrodes for research development. The potential of the working electrode (the electrode under test) is varied against a reference electrode, whose potential is fixed in the electrolyte. The current generated by the reaction occurring on the working electrode is transferred to a third electrode (the counter electrode) which adapts its potential according to the current and the resistivity of the electrolyte. This method enables isolating the process at the working electrode and disregards the losses related to the reaction occurring on the counter electrode.

When the applied potential reaches a certain potential below the reduction potential of water, i.e. $0 \mathrm{~V}$ vs. the reversible hydrogen reference electrode (RHE), water molecules or protons can start to react on the cathode, resulting in a negative measured current (i.e. electrons moving from the electrode into the electrolyte). This current increases in magnitude when shifting the potential cathodically as the driving force for reduction is enhanced. We define here the overpotential for reduction, $\eta_{\text {red }}$, as the difference of potential between that which is applied and the thermodynamic reduction potential of water to reach a certain current density (e.g. $-10 \mathrm{~mA} \mathrm{~cm}^{-2}$ in our example in Fig. 2c). Analogously, when probing the anode as the working electrode, a positive current can onset once the potential exceeds the thermodynamic potential of water oxidation $(1.229 \mathrm{~V}$ vs RHE), when water molecules or hydroxyl anions are converted to $\mathrm{O}_{2}$ on the anode material. The overpotential for water oxidation, $\eta_{\mathrm{ox}}$, is therefore defined as the difference of between the potential applied and the potential of water oxidation, to reach a certain current density $(+10 \mathrm{~mA}$ $\mathrm{cm}^{-2}$ in our example).

The overall voltage required, shown in Fig. 2c, corresponds to the voltage needed to operate an electrolyzer with a certain current density (e.g. $\left.10 \mathrm{~mA} \mathrm{~cm}^{-2}\right)$ ignoring the ohmic losses in the electrolyte or membrane. It equals the sum of the reversible potential for water reduction and oxidation $(1.229 \mathrm{~V})$ and the overpotentials for the reduction and oxidation reactions. This overall voltage must be minimized in order to increase the energy conversion efficiency, consequently decreasing the price of the storage. While additional overpotential can arise from ohmic losses due to the electrolyzer geometry, bubble formation, or ion conduction in the membrane and in the electrolyte, these can be reduced through cell engineering. Indeed the most significant losses come from the overpotentials required to kinetically activate the electrochemical reactions. The charge trans- fer between the chemical species and the electrodes requires overcoming an energy barrier that depends strongly on the catalytic properties of the electrode materials. Usually, the anodic half-reaction requires a much higher activation overpotential than the cathodic half-reaction due to the complex multi-electron transfer route required to form molecular $\mathrm{O}_{2} \cdot{ }^{[11,14]}$ The next sections will thus accordingly focus on the catalytic properties of materials developed as water splitting electrodes, with particular emphasis on those used for the most energy demanding reaction, water oxidation.

\section{Electrode Materials for Alkaline Electrolysis}

The requirements to select electrode materials for alkaline water electrolysis include good corrosion resistance, high electronic conductivity and high catalytic activity with regard to the two reactions of interest (the hydrogen evolution reaction, HER, at the cathode and the oxygen evolution reaction, OER, at the anode). As mentioned before, the overall water splitting reaction is mainly limited by the slow kinetics of the OER at the anode. ${ }^{[11,14]}$ Therefore tremendous research efforts have been dedicated to the search of a low-cost and efficient electrocatalyst for oxygen evolution.

Stainless steel and lead oxide were first identified as inexpensive electrode materials, with relatively low overpotential for the OER, but their chemical stability at sufficiently high voltage in highly concentrated alkaline solutions limit their applicability. Nowadays, $\mathrm{IrO}_{2}$ and $\mathrm{RuO}_{2}$ are considered the benchmark materials for OER in alkaline conditions, presenting overpotentials of 0.32 and $0.29 \mathrm{~V}$ respectively for a current density of $10 \mathrm{~mA} \mathrm{~cm}^{-2} \cdot{ }^{[15,16]}$ The activity of iridium-based electrodes towards 
oxygen evolution has been shown to be independent of $\mathrm{pH}$, widening the potential application of this material..17] Nevertheless, these precious metals do not show unlimited stability in alkaline solutions, ${ }^{[18]}$ are costly, and their supply is not sustainable. Therefore, they are not suitable for largescale TW applications. In order to find a low-cost OER electrocatalyst, researchers are now concentrating their efforts on firstrow transition metals and their composites, for instance cobalt phosphate composites, nickel borate, cobalt oxide nanoparticles and manganese oxide thin films. ${ }^{[19-22]}$ All these materials offer satisfying OER activity, with overpotentials lower than $0.4 \mathrm{~V}$ for a current density of $10 \mathrm{~mA} \mathrm{~cm}$, and significantly lower fabrication costs when compared to ruthenium- or iridium-based materials.

Recently, Jaramillo and coworkers tested a large range of first row transition metals for the OER in both alkaline and acidic conditions. ${ }^{[15,16]}$ All electrode materials were electrodeposited on glassy carbon (GC) substrates using a similar protocol for each of them, in order to benchmark the assessment and the performance of anode materials for water oxidation. Due to the highly oxidizing conditions experienced during OER, the electrocatalysts are likely converted to oxides or oxyhydroxides but they are named according to their metal composition for simplicity. Comparison of the electrode activities in $1 \mathrm{M} \mathrm{NaOH}$ is shown on Fig. 3. The magnitude of the overpotential required to achieve a current density of $10 \mathrm{~mA} \mathrm{~cm}^{-2}$ after 2 hours of operation is shown on the y-axis while the same overpotential recorded immediately after immersion in the electrode is shown on $\mathrm{x}$-axis. This type of plot gives valuable information on both electrode performance and short-term stability, i.e. if there is no change in activity, the material is represented on the black dotted $45^{\circ}$ line.

Except for ruthenium, most catalysts tested in this study can achieve the chosen current density at an overpotential between 0.35 and $0.5 \mathrm{~V}$, which is slightly higher than the target overpotential selected in this study $(0.35 \mathrm{~V}$, represented by the dashed blue lines in Fig. 3). However, one can notice the good performance of NiMoFe, the only non-noble metal catalyst able to function at a potential below the target, during initial test and after two hours of operation. This result is even more encouraging taking in account that the active area (real area $\times$ roughness factor) was smaller than the one measured for the ruthenium reference electrode, which means that the specific catalytic activity (activity normalized to the active area) was actually higher. Other promising materials that demonstrated overpotentials lower than $0.4 \mathrm{~V}$ include $\mathrm{Co}-\mathrm{P}, \mathrm{CoFe}, \mathrm{NiCo}, \mathrm{NiFe}$ and $\mathrm{NiFeCo}$. It is

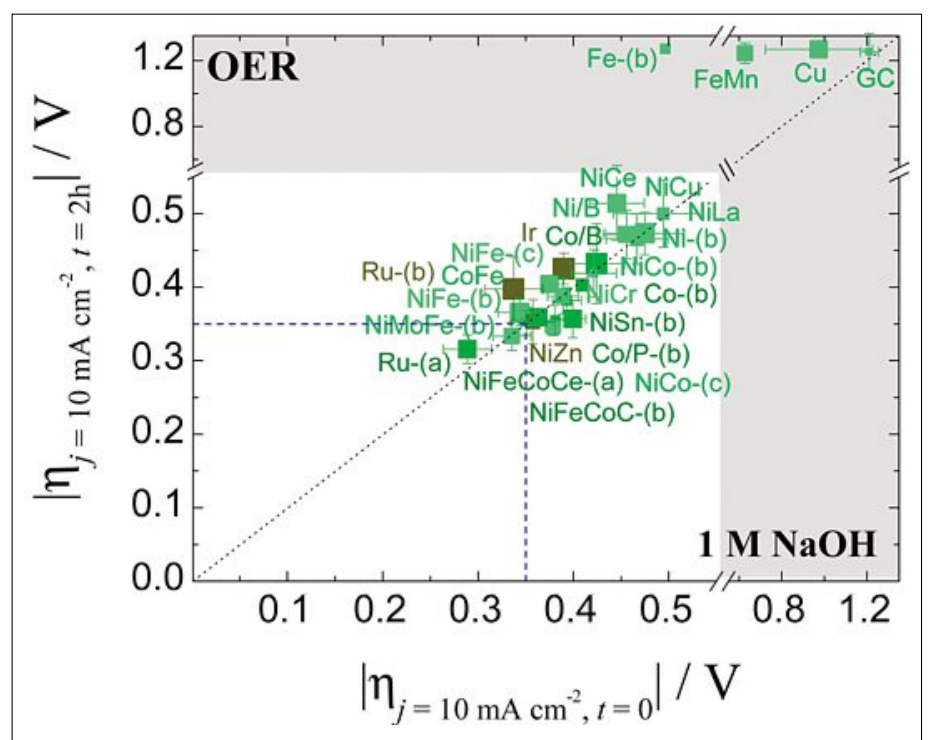

Fig. 3. OER catalytic activity of electrodeposited materials after $2 \mathrm{~h}$ of operation is shown against the catalytic activity measured immediately after immersion in alkaline solution. The dotted line represents the ideal stability with no change in activity during the 2 first hours of operation and the color scale is indicative of the thin film roughness (pale green to black increasing roughness). Reprinted with permission from J. Am. Chem. Soc. 2015, 137, 4347-4357. Copyright 2015 American Chemical Society.

worth noting that all the aforementioned materials succeed in showing good stability in performance over long term measurements $(24 \mathrm{~h})$, except for $\mathrm{NiCo}$ and $\mathrm{NiFeCo}$.

From this report, nickel-, iron- and cobalt-based electrodes, especially the ones containing two or three different metals, seem to have the best catalytic properties towards OER in alkaline solution. This was corroborated by recent studies of iron-nickel alloys that showed considerable catalytic performance. Maximum performance was obtained for films or particles containing between 30 and $40 \% \mathrm{Fe}$, achieving $10 \mathrm{~mA}$ $\mathrm{cm}^{-2}$ at overpotentials below $300 \mathrm{mV}$. ${ }^{[23,24]}$ The iron incorporation inside the nickel oxide/hydroxide layer has been evidenced to modify the environment of the $\mathrm{Ni}-\mathrm{O}$ bond, reducing the electrochemical oxidation of $\mathrm{Ni}(\mathrm{OH})_{2}$ to $\mathrm{NiOOH},{ }^{[24]}$ and activating $\mathrm{Ni}$ catalytic centers (probably $\mathrm{Ni}^{2+}$ ) throughout the catalytic film. ${ }^{25]}$ These results are also consistent with the better performance of Ni films after aging, which indicates that previous reports of highly active $\mathrm{Ni}(\mathrm{OH})_{2}$-based OER catalysts include Fe impurities. ${ }^{[24,25]}$ Using this material, Lu et al. have recently obtained the highest catalytic activity for non-noble metal electrodes, when electrodeposited $\mathrm{NiFe}$ onto a nickel foam mesostructure, with a record current density of $500 \mathrm{~mA} \mathrm{~cm}^{-2}$ at an overpotential of only $240 \mathrm{mV}$ in $10 \mathrm{M} \mathrm{KOH.}$ [26] $^{\text {[26 }}$

Another study of nickel-iron electrodes for oxygen evolution evidenced an additional feature of highly active materials for this application using SQUID magnetometer measurements. [27] This technique allows the detection of extremely subtle magnetic susceptibility inside the material induced by an external magnetizing field (H). Fig. 4 shows the magnetic response of three NiFe electrodes, electrodeposited at a constant current density of either $25 \mathrm{~mA}$ $\mathrm{cm}^{-2}$ or $250 \mathrm{~mA} \mathrm{~cm}^{-2}$ in presence of ammonium sulfate (sample $\mathrm{A}$ and $\mathrm{C}$ respectively), as well as a reference sample deposited at $105 \mathrm{~mA} \mathrm{~cm}^{-2}$ without $\left(\mathrm{NH}_{4}\right)_{2} \mathrm{SO}_{4}$. The good performance of the electrodeposited samples with the ammonium salt have been correlated to the ferro/ferrimagnetism exhibited by sample $\mathrm{A}$ and $\mathrm{C}$ at 300 $\mathrm{K}$. In contrast, sample B shows paramagnetic behavior, reflecting the chemical and physical complexity of the catalyst and the slight changes in crystal organization depending on the deposition parameters.

Theoretical modeling and experiments have also evidenced a transition through high spin states in the $\mathrm{CaMn}_{3} \mathrm{O}_{4}$ catalytic cluster of Photosystem II during water oxidation.[28,29] Oxygen-activating enzymes have also been characterized with a highspin heme iron, non-heme iron and copper catalytic sites. ${ }^{[30,31]}$ Therefore, the correlation between the ferromagnetic character and suitable catalytic properties in $\mathrm{NiFe}$ electrodes suggest strongly that the high spin states in the catalyst facilitate the electron spin inversion required for oxygen evolution. Further investigations are nevertheless necessary to characterize the desired properties for the catalyst and to fully understand the $\mathrm{O}_{2}$ formation mechanism.

The considerable catalytic performance of nickel iron alloys for the OER reaction renewed the interest in inexpensive and large-scale produced materials 


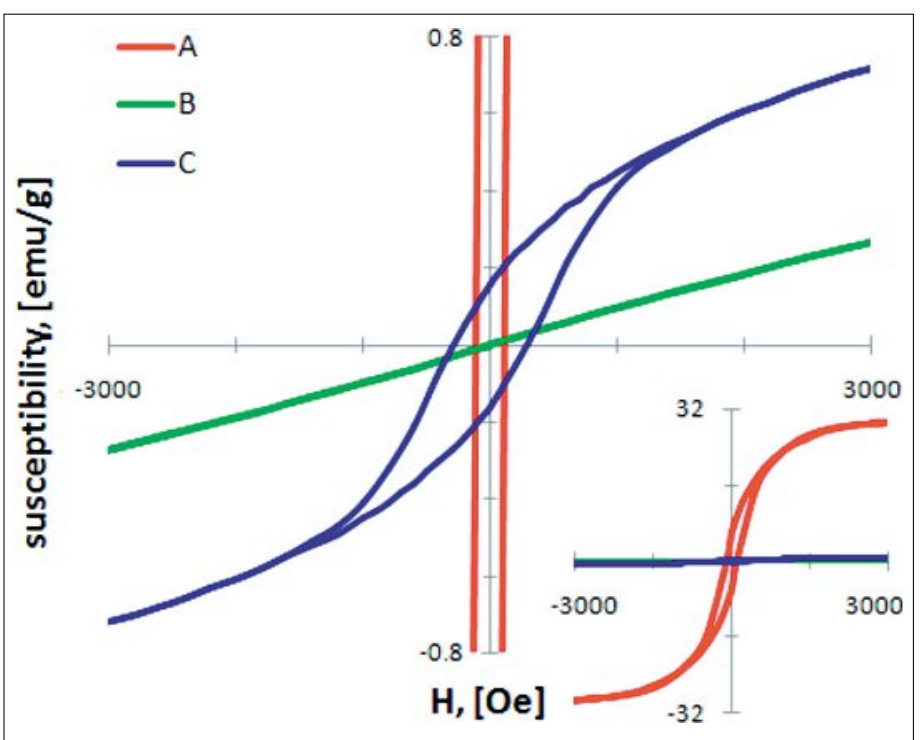

Fig. 4. SQUID field sweep of NiFe oxide electrodeposited in different conditions: $\mathrm{A}$, at $25 \mathrm{~mA} \mathrm{~cm}^{-2}$ with $25 \mathrm{mM}\left(\mathrm{NH}_{4}\right)_{2} \mathrm{SO}_{4}$, $B$ at $105 \mathrm{~mA} \mathrm{~cm}^{-2}$ without any salt and C, $250 \mathrm{~mA} \mathrm{~cm}^{-2}$ with $25 \mathrm{mM}\left(\mathrm{NH}_{4}\right)_{2} \mathrm{SO}_{4}$. The inset provides a better perspective of the scale of sample A's magnetization. Reprinted with permission from $J$. Phys. Chem. C 2008, 112, 3655-3666. Copyright 2008 American Chemical Society.

such as nickel containing stainless steel: AISI $304(8 \% \mathrm{Ni}, 18-20 \% \mathrm{Cr})$, AISI 316 $(10 \% \mathrm{Ni}, 18 \% \mathrm{Cr})$ and AISI 316L (same as 316 , low in carbon). Two recent studies ${ }^{[32,33]}$ show that steel samples require a pretreatment to form an oxide layer at the surface, which acts as the catalyst. Electrooxidation of an AISI 304 metal alloy under particularly harsh conditions (at a current density of $\sim 1.8 \mathrm{~A} \mathrm{~cm}^{-2}$ in $7.2 \mathrm{M} \mathrm{NaOH}$ for $300 \mathrm{~min}$ ), results in the formation of an ultrathin film, depleted of $\mathrm{Cr}$ on the surface and composed of $67 \% \mathrm{Ni} / 33 \% \mathrm{Fe}$. Catalytic performance of such film (named Elox300) is compared to untreated AISI 304 alloy in Fig. 5. The surface-modified metal sample exhibits remarkable current voltage characteristics, achieving $10 \mathrm{~mA}$ $\mathrm{cm}^{-2}$ at an overpotential of $270 \mathrm{mV}$ in 0.1 $\mathrm{M} \mathrm{KOH}$, and $12 \mathrm{~mA} \mathrm{~cm}^{-2}$ at only $212 \mathrm{mV}$ in $1 \mathrm{M} \mathrm{KOH} .{ }^{[32]}$ These surface-oxidized steel samples proved to be inert. Moreover, X-ray photoelectron spectroscopy (XPS) performed on this film suggest that $\gamma$-NiOOH constitutes the catalytic active species on the surface of the electrode, consistent with the negative current wave observed at potential 1.2-1.42 V vs. RHE (Fig. 5), which is attributed to the Ni(III)/ $\mathrm{Ni}(\mathrm{II})$ redox couple.

Nickel enrichment of the steel surface was also obtained upon aging a film of AISI 316L in $5 \mathrm{M}$ LiOH electrolyte at 0.8 $\mathrm{V}$ vs. $\mathrm{Hg} / \mathrm{HgO}$ reference electrode ( $c a .1 .7$

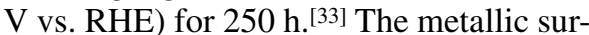
face composition was found to be $83 \% \mathrm{Ni}$, $10 \% \mathrm{Fe}$ and $7 \% \mathrm{Cr}$ and $\mathrm{Ni}(\mathrm{OH})_{2}, \mathrm{NiOOH}$, $\mathrm{FeOOH}$ as well as $\mathrm{Cr}_{2} \mathrm{O}$ were detected in the oxide layer with XPS. Such film shows high electrocatalytic activity towards OER after an induction time of $250 \mathrm{~h}$ and stable performances over $3000 \mathrm{~h}$ of operation.

The increase in OER activity for the aged and pretreated steel films have been rationalized with the increase in roughness and a synergetic effect (hypo-hyper $d$-orbital interbonding effect) due to the presence of dispersed $\mathrm{Fe}$ and/or $\mathrm{Cr}$ in the oxide layer. These recent results, especially those concerning the stability of the samples, hold significant promise for highperformance OER catalyst in the future and should be further studied to uncover the full potential of low cost steel electrodes.

In addition to the development of conventional alkaline electrolysis cells operating at temperatures below $100{ }^{\circ} \mathrm{C}$, researchers are also exploring hightemperature electrolysis (keeping concentrated $\mathrm{KOH}$ as the electrolyte). Increasing the operating temperature over $100{ }^{\circ} \mathrm{C}$ modifies the thermodynamics of the system (reducing the potential required) and enhances electrode performance by accelerating kinetic processes. Particularly, ionic conductivities of $\mathrm{NaOH}$ and $\mathrm{KOH}$ solutions are increased significantly when the temperature reaches $200-250{ }^{\circ} \mathrm{C} .{ }^{[34]}$ For the electrolyte to remain in the liquid phase, it is necessary to apply high pressure (30-100 bars) ${ }^{[35]}$ or to immobilize the electrolyte in porous material such as strontium titanate $\left(\mathrm{SrTiO}_{3}\right)_{\cdot}{ }^{[36]}$ Moreover, the relative volume of the formed hydrogen or oxygen gas bubbles is also lowered with increasing pressure, which subsequently decreases losses in the catalytic area of the cell (ohmic losses). ${ }^{[37]}$ The effect of temperature has been shown to be more pronounced on the oxygen evolution reaction than the hydrogen evolution reaction: for a current density of $0.25 \mathrm{~A} \mathrm{~cm}^{-2}$ applied on polished Ni electrodes, the anodic overpotential decreases from $0.53 \mathrm{~V}$ to less than $0.05 \mathrm{~V}$, whereas the cathodic was reduced from -0.43 to $-0.19 \mathrm{~V}$ by increasing the temperature from 80 to $264^{\circ} \mathrm{C}$. ${ }^{[38]}$ In terms of cathode materials, nickel alloys (Ni-Ti, $\mathrm{Ni}-\mathrm{Co}$ and Ni-Mo) have demonstrated slightly better performance than pure nickel at high temperature. ${ }^{[35,39,40]}$ For anodes, spinel and perovskites structured materials, such as $\mathrm{Co}_{3} \mathrm{O}_{4}, \mathrm{NiCo}_{2} \mathrm{O}_{4}, \mathrm{LaNiO}_{3}$ and $\mathrm{La}_{0.5} \mathrm{Ni}_{0.5} \mathrm{CoO}_{3}$ were shown to provide the lowest overpotential as compared to pure nickel electrodes. ${ }^{[35,41,42]}$ However, the increased thermal degradation at high temperature may be problematic for largescale application.

\section{Electrode Materials for PEM Electrolysis}

Historically, alkaline electrolyzers have been the first widely developed devices for water electrolysis and still make up most of the electrolyzers that can be found on the market nowadays. As discussed before, the design of such cells, see Fig. 2, offers several advantages, including an inexpensive microporous ceramic diaphragm and electrodes that can be made of relatively simple and cheap materials such as nickel,

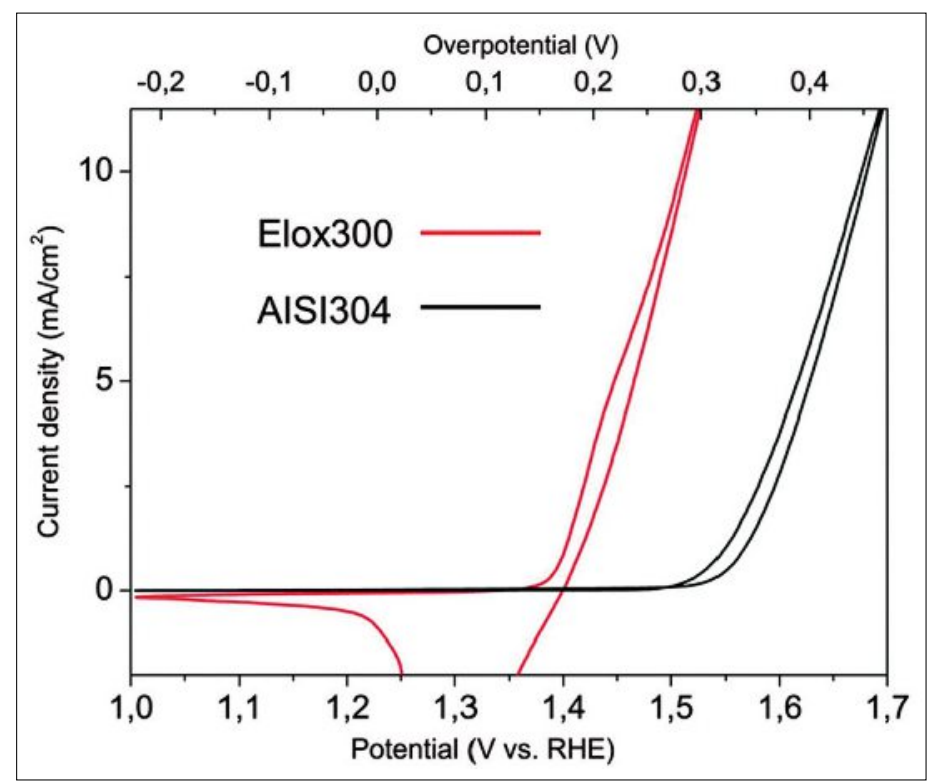

Fig. 5. Cyclic voltamograms of AISI 304 alloy and pretreated AISI 304 sample (electroxidized at $1.8 \mathrm{~A} \mathrm{~cm}^{-2}$ in $7.2 \mathrm{M}$ $\mathrm{NaOH}$ for $300 \mathrm{~min}$ ) The recorded current density is shown against the applied potential with respect to RHE (bottom) and the overpotential (top axis). Reproduced from Energy Environ. Sci. 2015, doi: 10.1039/C5EE01601K with permission of The Royal Society of Chemistry. 
stainless steel or other first row transition metal oxides. ${ }^{[41,43,44]}$

However, this technology presents at least three major drawbacks. ${ }^{[12,43]}$ (1) The output current density is relatively low (typically $0.2-0.4$ A.cm-2 ${ }^{-2}$. This is mostly due to large ohmic losses across the electrolyte and thick diaphragm (typically between $500 \mathrm{~nm}$ and $1 \mu \mathrm{m}$ to efficiently prevent gas diffusion). (2) It is impossible to operate at high pressure. This prevents the creation of a compact system, and forces the post-compression of hydrogen for storage. (3) It has a very low partial-load range, because under low load (usually $<40 \%$ of the nominal load), the oxygen production rate is low enough that the small amount of hydrogen diffusing through the diaphragm (independent of the load) can create an explosive mixture $\left(>4 \% \mathrm{H}_{2}\right.$ in $\left.\mathrm{O}_{2}\right)^{[45]}$ in the system. This makes alkaline electrolyzers less suitable for the dynamic requirements of storing the highly variable renewable energy.

To address these three issues, a different design has been proposed as a promising alternative: the proton-exchange membrane (PEM) electrolyzer. The configuration of a PEM electrolyzer is depicted in Fig. 2. In this design, water circulates through the anode, while the hydrogen is produced in a dry environment at the cathode. Similarly to the alkaline design, the anode and cathode are coated with electrocatalysts for the OER and HER respectively. Nevertheless, a major difference with alkaline electrolysis lies in the presence of a solid electrolyte: a very thin (20-300 nm) humidified acidic membrane (typically Nafion $\left.{ }^{\mathrm{TM}}\right),{ }^{[46,47]}$ transports protons from the anode to the cathode, where they directly recombine with electrons from the external circuit to yield gaseous hydrogen. This proton-exchange membrane is also responsible for the acidic environment in which the electrodes are required to function. PEM electrolyzers possess several advantages compared to their alkaline counterparts. First they can operate at much higher current densities (typically higher than $\left.2 \mathrm{~A} \mathrm{~cm}^{-2}\right),{ }^{[48,49]}$ which allows operational cost reduction. This improvement comes from the much lower thickness and much higher conductivity of the PEM compared to the alkaline diaphragm, which in turn reduces ohmic losses between the electrodes. Second, it can operate under much higher pressures (up to 350 bar), ${ }^{[52]}$ and even under differential pressure, where only the cathode size is pressurized to extract hydrogen without producing dangerous pressurized oxygen on the anode side. Finally, and perhaps most importantly, the PEM has an extremely low permeability to hydrogen. ${ }^{[50,51]}$ This ensures a very high purity of the output hydrogen stream, while removing the safety issues associ- ated with gas mixing. Moreover, it allows the electrolyzer to function under a wide range of partial load and even potentially under overload. This makes the system very dynamic as it can adapt to large input current variations. On the other hand, PEM electrolyzers still present one big drawback compared to the alkaline alternative: they are much more expensive due to the very acidic operation regime imposed by the membrane. Indeed this prevents the use of most metals - which would quickly corrode during operation, especially under the oxidative conditions at the anode - and forces the use of more expensive materials for the electrodes (typically titaniumbased alloys) and the electrocatalysts, as will be developed further in this section.

Despite its higher cost, the PEM electrolyzer design is very attractive when it comes to running the device with a renewable source of electricity. Indeed, the intermittency of wind and, especially, solar energy makes them very hard to use efficiently with an alkaline electrolyzer that has to be shut down under $40 \%$ partial load for safety reasons. ${ }^{[12]}$ On the other hand, PEM electrolysis can be performed under almost any fraction of the nominal load (although the range does decrease with increasing pressure). ${ }^{[47]}$ This ability, coupled with the very quick response of electrochemical reactions and proton transport to changes in current density (contrary to the much more inert ion transport in liquid electrolytes), makes the PEM electrolyzer a very attractive candidate for the renewable production of highly pure and already-compressed hydrogen gas (e.g. in a PV + electrolyzer configuration).

The first report of a PEM electrolyzer goes back to 1973 and already produced much higher current densities than stateof-the-art alkaline electrolyzers $\left(1 \mathrm{~A} \mathrm{~cm}^{-2}\right.$ for an applied voltage of $1.88 \mathrm{~V}$ ) that were reported to be stable for over $15000 \mathrm{~h} \cdot{ }^{[12]}$ Unfortunately, due to the previously mentioned tendency of most metals to corrode in acidic conditions, the authors had to use platinum black as the HER catalyst and iridium as the OER catalyst. Since this first report, the very high cost of catalysts based on the platinum group metals (PGM) has remained one of the biggest obstacles to the development of cost-efficient PEM electrolyzers. Indeed, even in more modern commercial electrolyzers, PGM catalysts still represent a significant portion of the overall material cost, ${ }^{[52]}$ despite their relatively low loading: $c a .2 \mathrm{mg} \mathrm{cm}^{-2}$ for the $\mathrm{Pt}$ at the cathode, and $c a .6 \mathrm{mg} \mathrm{cm}^{-2}$ of Ir at the anode. Moreover, and perhaps more importantly, beyond the cost of these PGMs, their scarcity (especially for Ir) completely prevents their use on the global scale associated with a hydrogen-based economy. This is the reason why research laboratories have been and are still looking for alternative catalytic materials able to completely replace the current generation of PGM catalysts. In the next paragraph, we will therefore present the progress made over the last four decades in catalyst optimization for the HER and OER in acidic conditions.

The highly acidic environment created by the membrane is favorable to HER catalysis, since it is typically easier to reduce protons to hydrogen when they are present at high concentration. Platinum is well known for being an extremely efficient catalyst for water reduction, with an overpotential $\left(\eta_{\text {red }}\right)$ lower than $0.05 \mathrm{~V}$ to produce a current density of $10 \mathrm{~mA} \mathrm{~cm}$ in $1 \mathrm{M} \mathrm{H}_{2} \mathrm{SO}_{4}$. In fact, to date, it is still the best monoatomic catalyst available for HER. As such, it has been traditionally used at the cathode of PEM electrolyzers developed at the laboratory scale, but its scarcity prevents a realistic use on a large scale. Still, its performance is usually used as the benchmark that alternative cheaper materials should approach. In addition to its prohibitive cost, platinum suffers from being very easily poisoned by trace amounts of metallic contamination in the feed water. Metallic ions will indeed undergo underpotential deposition (UPD) and completely cover the surface of the platinum, seriously decreasing its catalytic performance. For these reasons, a considerable amount of work has been dedicated to designing and optimizing robust earth-abundant electrocatalysts able to compete with the efficiency of platinum. Typically non-noble metal catalysts are constructed around $\mathrm{Fe}$, $\mathrm{Ni}, \mathrm{Cu}, \mathrm{Co}, \mathrm{Mo}$ and $\mathrm{W}$, which are orders of magnitude more abundant than $\mathrm{Pt}$ in the Earth's crust, with $\mathrm{Fe}$ and Ni being the most abundant among them. Since none of these elements is a good HER catalyst by itself, it is necessary to combine them with others to produce competitive materials. Recently, molybdenum disulfide $\left(\mathrm{MoS}_{2}\right)$ has received a lot of attention. For a long time, it was considered to be completely inactive towards the HER. While this is true for bulk crystalline $\mathrm{MoS}_{2}$, it was predicted in 2005 ${ }^{[53]}$ and shown in 2007[54] that $\mathrm{MoS}_{2}$ was actually very active under its nanocrystalline morphology. More specifically, the edge sites of $\mathrm{MoS}_{2}$ nanoflakes have been demonstrated to be responsible to this catalytic behavior. Since then, $\mathrm{MoS}_{2}$ has been extensively studied, and has been reported with very good performances in acidic electrolyte: a current of $10 \mathrm{~mA} \mathrm{~cm}^{-2}$ was obtained for $\eta_{\text {red }}<0.2 \mathrm{~V}$ with chemically exfoliated $\mathrm{MoS}_{2} \cdot{ }^{[55,56]}$ Interestingly, amorphous molybdenum sulfide, $\operatorname{MoS}_{x}$, also produces very good catalytic water reduction, with a reported current of $15 \mathrm{~mA} \mathrm{~cm}^{-2}$ at $\eta_{\text {red }}=0.2 \mathrm{~V}$. ${ }^{[57]}$ In another work, a nickel-molybdenum nitride cata- 
lyst was reported to produce $c a$. $4.5 \mathrm{~mA}$ $\mathrm{cm}^{-2}$ at $\eta_{\text {red }}=0.2$ V. ${ }^{[58]}$ Nickel phosphide $\left(\mathrm{Ni}_{2} \mathrm{P}\right)$ and cobalt phosphide $(\mathrm{CoP})$ have also been recently reported with excellent catalytic abilities. Nanostructured $\mathrm{Ni}_{2} \mathrm{P}$ was measured to produce $20 \mathrm{~mA} \mathrm{~cm}{ }^{-2}$ at $\eta_{\text {red }}=0.13 \mathrm{~V},{ }^{[59]}$ and was measured, by a different group, to be stable for more than two days. ${ }^{60]}$ On the other hand $\mathrm{CoP}$ has been reported to produce $10 \mathrm{~mA} \mathrm{~cm}^{-2}$ at $\eta_{\text {red }}=85 \mathrm{mV} \cdot{ }^{[61]}$ Other efficient catalysts reported in the recent literature are listed in a review from 2015 by Zou and Zhang. ${ }^{[62]}$ A more direct and accurate comparison of the performances of different HER catalysts in acidic conditions has been recently published by Jaramillo and coworkers (Fig. 6). ${ }^{[15]}$ In this study they benchmark the currents produced by several materials under identical conditions. Unsurprisingly, platinum remains the best HER catalyst, but interestingly, several alloys, such as NiMo, CoMo, NiCoMo or NiW come very close in performance, and also display very good stability. Overall, a variety of very good alternative materials have been proposed to replace $\mathrm{Pt}$ as HER catalyst in acidic conditions. Moreover, given the scalable deposition of most of these materials, it seems like they could be easily applied on an industrial scale.

Unfortunately, replacing PGM as catalyst for OER is a much tougher challenge. Indeed, as mentioned before, most metals are easily corroded under oxidative conditions in acid. Since the oxidation of the metal is easier than the oxidation of water, the catalyst oxidizes and since most metal cations are soluble in acid the electrode dissolves into the electrolyte. State-of-the-art OER acid catalysis has been achieved with iridium or iridium oxide since the very early work on PEM electrolysis. Despite the large amount of work produced in the field since these first reports, and contrary to the success encountered with earth-abundant HER catalysts, no viable replacement has been found so far. Iridium being the rarest element in the Earth's crust, replacing it with any other element would already represent progress. Ruthenium has been found to be more active than iridium, but it has also been found to corrode after some time. ${ }^{[63,64]}$ On the hand, Ir-Ru binary mixtures show very good catalytic properties and stability, ${ }^{[65,66]}$ for an Ir content as low as $20 \mathrm{~mol} \%$. However, ruthenium is almost as scarce as iridium and does not really represent a viable replacement for largescale applications. Other works reported that diluting Ir in even more abundant elements, such as $\mathrm{Nb},{ }^{[67]}$ or $\mathrm{Sb}^{[68]}$ was also a viable approach to reduce Ir content in the catalyst. An interesting study described a mixture of $\mathrm{SnO}_{2}, \mathrm{Ta}_{2} \mathrm{O}_{5}$ and $\mathrm{IrO}_{2}$ that performed efficiently even at low Ir content (15\%). ${ }^{[69]}$ Unfortunately, in the past de-

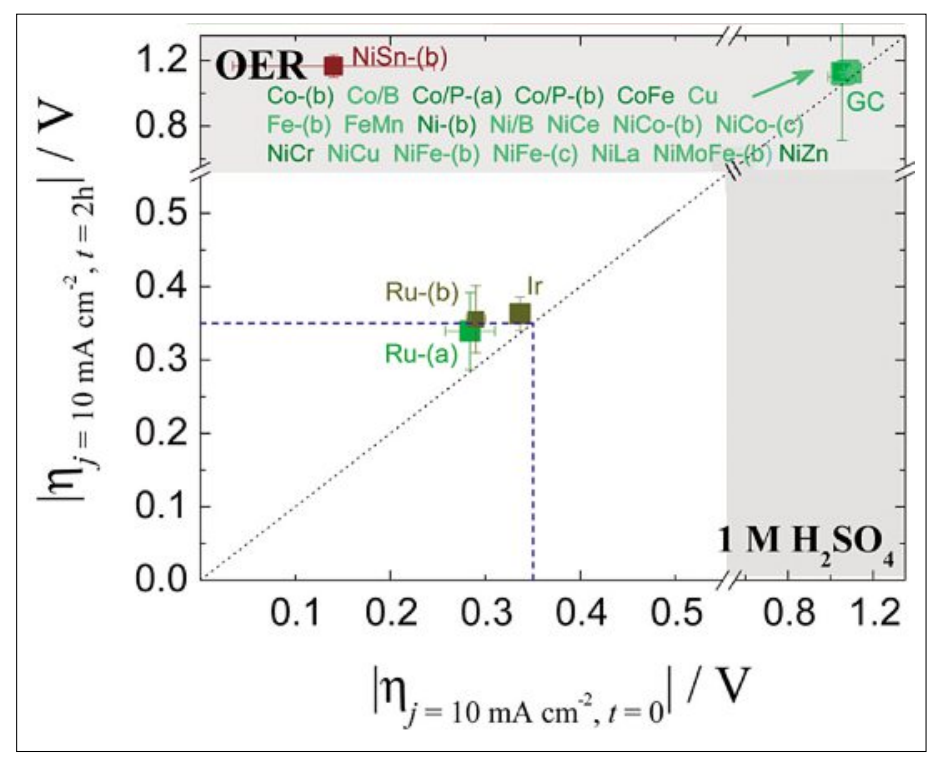

Fig. 6. OER catalytic activity of electrodeposited materials after $2 \mathrm{~h}$ of operation is shown against the catalytic activity measured immediately after immersion in sulphuric acid solution. The dotted line represents the ideal stability with no change in activity during the 2 first hours of operation and the different colors are indicative of the thin film roughness (pale green to black increasing roughness). Reprinted with permission from J. Am. Chem. Soc. 2015, 137, 4347-4357. Copyright 2015 American Chemical Society.

cades, no alternative metal or metal oxide has been found to come anywhere close to iridium, or ruthenium, in performances, as illustrated in Fig. 6.

Overall, PEM electrolysis seems to be the most promising short term option for the large-scale production of high-purity hydrogen, especially in the context of the development of renewable energy sources. Indeed, the PEM technology is better adapted to deal with the intermittent current typically provided by these sources, as it can very quickly adapt to any change in input current, without creating explosion hazards in the system. However, the material cost of PEM devices remains high, and electrocatalyst coatings - although they represent a tiny fraction in mass-still represent a significant fraction of the overall cost. More precisely, while cheap HER catalysts have been developed in recent year, and seem very likely to be introduced in industrially produced electrolyzers, there is still no viable replacement for iridium-based electrocatalysts at the anode. Finding an earth-abundant OEC (Oxygen Evolution Catalyst) able to operate in acidic conditions would accelerate significantly the development of the water electrolysis technology, and as such, remains a critical field of research.

\section{Water Splitting in Other Conditions: Sea Water / Neutral pH}

As previously discussed, extreme $\mathrm{pH}$ and high purity water systems are efficient for water electrolysis but the cost of such systems with, for example expensive ion- selective membranes or catalysts may be limiting large-scale application. Moreover, impurities in the water feedstock can dramatically decrease the lifetime of electrochemical cells. As such, water splitting electrocatalysts have been studied in neutral $\mathrm{pH}$ conditions. Neutral $\mathrm{pH}$ media are promising systems since they are less corrosive toward active materials (for example catalysts) and other system components (for example: piping). ${ }^{770]}$ However, no efficient and safe electrolysis in a sustained $\mathrm{pH}$-neutral environment has been yet developed. Therefore, taking advantage of the large amount of water on earth, it is crucial to study systems that are sustainable and do not require expensive equipment for water electrolysis. Most of the time, depending on the source, seawater contains many species such as $\mathrm{Na}^{+}, \mathrm{Cl}^{-}$, $\mathrm{Mg}^{2+}, \mathrm{Ca}^{2+}, \mathrm{K}^{+}, \mathrm{SO}_{4}{ }^{2-}, \mathrm{Br}^{+}, \mathrm{CO}_{3}{ }^{2-}$. The latter chemicals might interfere with the water reduction (hydrogen evolution) and/or water oxidation (oxygen evolution).

In seawater, the large numbers of chlorine ions can be preferably oxidized (instead of $\mathrm{H}_{2} \mathrm{O}$ oxidation) because of the lower overpotential for chlorine evolution. Two main reactions can occur: chlorine evolution reaction (Eqn. (6)) and water oxidation reaction (Eqn. (7)):

$$
2 \mathrm{Cl}^{-} \rightarrow \mathrm{Cl}_{2(\mathrm{~g})}+2 \mathrm{e}^{-}
$$

$$
2 \mathrm{H}_{2} \mathrm{O} \rightarrow 4 \mathrm{H}^{+}+\mathrm{O}_{2(\mathrm{~g})}+4 \mathrm{e}^{-}
$$


One approach to overcome the chlorine evolution is to insert a selective ion membrane in the electrochemical cell. The use of a cation-selective membrane was shown to be very beneficial in enhancing the oxygen evolution at the $\mathrm{IrO}_{2} / \mathrm{Ti}$ electrode as an anode. ${ }^{[71]}$ The surface of the latter electrode was modified by a perm-selective polymer (Nafion), which hinders chloride ion transport to the electrode surface and, as a result, suppresses chlorine evolution and increases oxygen evolution reaction by a factor of 2. Another study on the effect of ions contained in seawater was reported recently. ${ }^{[72]}$ The hydrogen evolution rate was observed to vary depending on the nature of ionic species. Especially in the presence of $\mathrm{MgCl}_{2}$ species, the hydrogen evolution rate was drastically lowered. For example, to overcome the problem, magnesium ion can be suppressed from seawater by polyelectrolyte multilayer membrane so that hydrogen evolution rate could be expected to increase. ${ }^{[73]}$ But the use of such additional membrane may increase the overall cost of production of water splitting. Another study focused on manganese-tungsten oxide for iridium oxide electrodes in a $0.5 \mathrm{M}$ $\mathrm{NaCl}$ at $\mathrm{pH} 8.0 .{ }^{[74]}$

Studies of oxygen-evolving catalysts in neutral and natural waters are important to lower the cost of hydrogen-based energy storage. ${ }^{[75]}$ Research of oxygen-evolving catalysts has been recently focused on active catalysts under neutral conditions. A facile method for deposition of a cobalt oxygen-evolving catalyst (Co-OEC) has been studied under $\mathrm{pH} 7$. The Co-OEC has shown high current density $\left(100 \mathrm{~mA} \mathrm{~cm}^{-2}\right.$ at an overpotential of $442 \mathrm{mV}$ ) in near neutral conditions ( $\mathrm{pH} 9.2)^{[22]}$ and in natural waters and seawater. ${ }^{[75]}$ Modest overpotentials at $1 \mathrm{~mA} \mathrm{~cm}^{-2}$ were observed with the Co-OEC compared to a standard $\mathrm{Ni}$ electrode in natural water and seawater. Nocera and co-workers also investigated an alternative to the Co-OEC by developing a nickel-borate oxygen-evolving catalyst that is stable under near neutral conditions ( $\mathrm{pH}$ 9.2). Ni-based oxide films evolves oxygen with a current density of $1 \mathrm{~mA} \mathrm{~cm}{ }^{-2}$ at an overpotential of $425 \mathrm{mV} \cdot{ }^{[76]}$ Another study showed an alternative with a silver oxygen-evolution catalyst (Ag-OEC) reaching an overpotential of $318 \mathrm{mV}$ at 1 $\mathrm{mA} \mathrm{cm}{ }^{-2}{ }^{[77]}$ More recently, a Janus cobaltbased catalyst was developed for water splitting in neutral conditions. It is the first time non-noble metal catalysts have been developed for both reduction and oxidation of water. The modest overpotentials achieved for both oxygen and hydrogen evolution are promising for photocatalysts systems and for lowering the cost of electrochemical systems. [78]

\section{Photoelectrochemical Water Splitting}

A simpler approach to convert renewable energy into a transportable fuel is to directly interface a semiconductor able to absorb light with an electrolyte to perform the water photolysis. This route could potentially reduce costs of building two separate devices and eliminate the losses related to the electricity transport between where the renewable energy is harvested and the electrolyzer, where it is converted into a fuel.[79]

Absorption of a photon in a semiconductor will promote an electron from the valence band to the conduction band, generating subsequently an electron-hole (or hole) in the valence band. These charge carriers can be separated spatially by the space charge field (an electric field produced by the equilibration of the semiconductor Fermi level and the electrolyte upon contact). With appropriate semiconductor band-edge positions (i.e. with a valence band lower in energy than the water oxidation potential and a conduction higher than the water reduction potential), the free photogenerated hole is then able to oxidize water while the electron can reduce water on the other side. This has been first dem- onstrated by Fujishima and Honda in 1972 using $\mathrm{TiO}_{2}$ in an aqueous electrolyte at $\mathrm{pH}$ 4.7.[80] $\mathrm{TiO}_{2}$ offers excellent stability under the harsh conditions of water spitting but suffers from its semiconductor band gap energy $(3.2 \mathrm{eV})$ that limits the maximum solar-to-hydrogen (STH) conversion efficiency to less than $2 \%$. Tremendous efforts have been deployed to find a material with high light absorption (low band gap), and electronic bands that straddle the water redox couples (band gap should be about $1.7-1.8 \mathrm{eV}$ to account for overpotentials). Unfortunately, this ideal material has not been developed yet.

This drawback can be addressed using two semiconductors in tandem to generate sufficient energy and also optimize the fraction of solar energy collected. A scheme representing the operational principle of a tandem cell using a n-type semiconductor as a photoanode and a p-type semiconductor as a photocathode is shown in Fig. 7a. The shorter wavelengths photons are absorbed in the first material (photoanode in our example), generating a hole that can oxidize water. Longer wavelengths, which have not been absorbed, are transmitted to the second electrode (photocathode), where the photogenerated electrons can reduce water. Both majority carriers (elec-

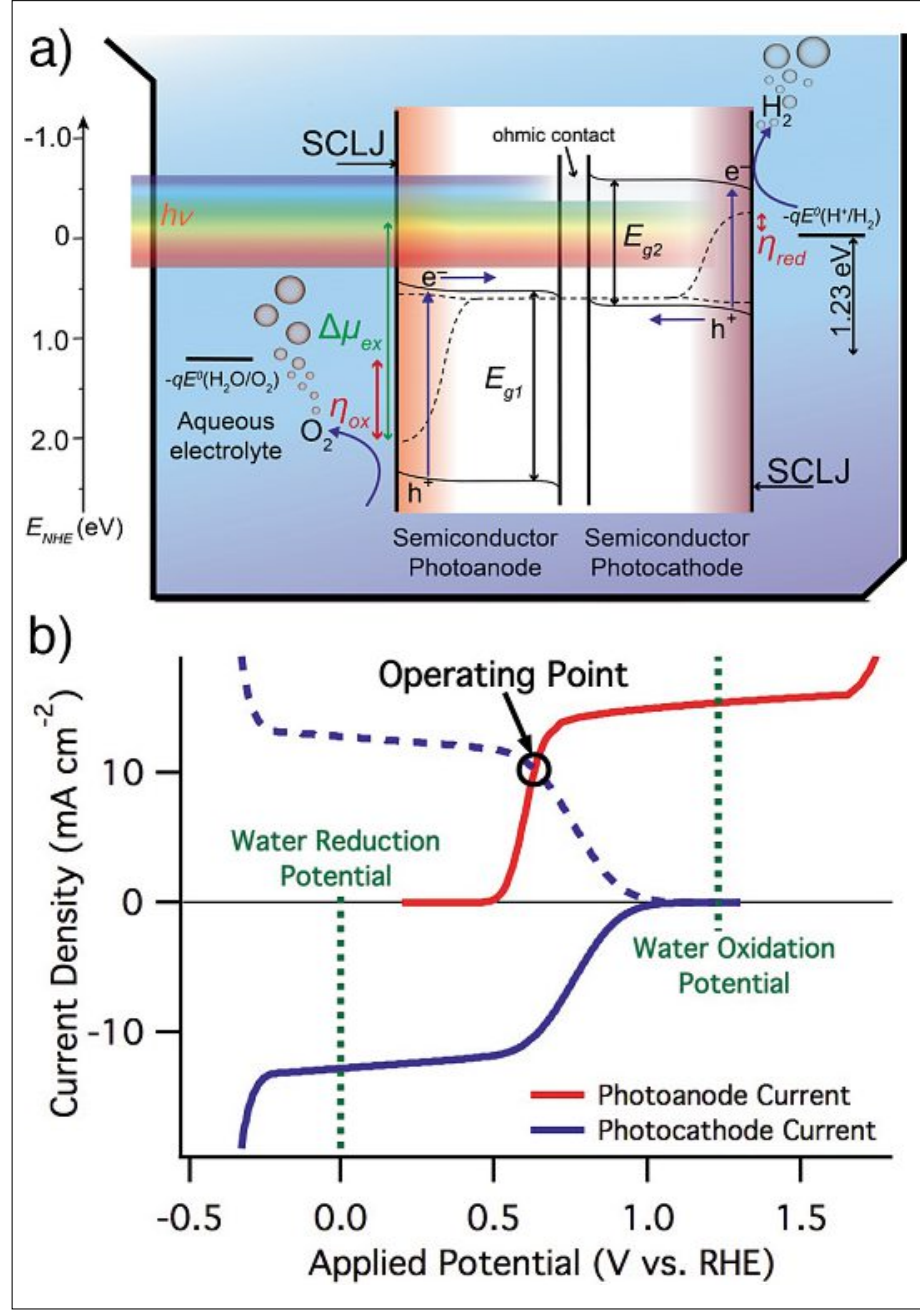

Fig. 7. a) Electron energy scheme of PEC water splitting using a dual-absorber tandem cell. Two photons, one absorbed in the photoanode, one in the photocatode, are used to build the necessary potential to dissociate water (Reprinted from $\mathrm{J}$. Phys. Chem. C 2013, 117, 17879-17893. Copyright 2013 the American Chemica Society). b) Typical current-voltage characterization of a photoanode (red) and a photocathode (blue) under illumination.

The current is shown against the potential applied to the electrode versus the RHE reference electrode. The tandem cell using the electrodes described in red and blue will operate at the current set by the crossing of the anodic photocurrent (red) and the inverse of the cathodic photocurrent (broken blue line). 
tron in a n-type photoanode and holes in a p-type photocathode) drift into the bulk of the semiconductor and recombine in order to close the electric circuit.

Specific performances of a typical photoanode and photocathode are shown in Fig. $7 b$, in red and blue respectively. The onset of the photocurrent appears below the energy of the respective redox couple (at potentials cathodic to $+1.229 \mathrm{~V}$ vs. RHE for the photoanode and anodic to $0 \mathrm{~V}$ vs. RHE for the photocathode), as the reaction is performed by the minority charge carriers (holes in the photoanode and electrons in the photocathode). The potential of an electrode being defined by the bulk Fermi level, that corresponds to majority carriers. In both cases, the photocurrent plateaus, depending on the conversion efficiencies and the light absorption of each material, before the onset potential of the dark current (sharp rise in current due to reaction with majority carriers).

Unlike the case for (dark) electrolysis electrodes, the overpotential is defined for a photoelectrode as the difference between the quasi Fermi level of the minority carriers and the redox energy level (see Fig. 7a). The operating potential and operating current of the cell is defined by the intercept of the photoanode current-voltage characterization with the inverse of the photocathode one (see Fig. 7b). The inverse of the cathodic current is used as the cathodic current is generally considered negative (electrons entering the electrode) whereas the anodic current is positive (electrons are extracted from the anode. This current will correspond to the amount of gas produced according to Eqns (1) and (2) in case of alkaline electrolyte (Eqns (3) and (4) in acidic conditions) and described in section 2.

For a tandem cell, as depicted in Fig. 7, calculations have predicted a maximum STH conversion efficiency of $21.6 \%$ assuming $1.0 \mathrm{eV}$ losses per photons (charge thermalization) using optimum band gap values of 1.89 and $1.34 \mathrm{eV}$ for the first and second absorber respectively. ${ }^{[79]}$ This corresponds to a certain improvement as compared to the $12.7 \%$ resulting from calculations performed for a single semiconductor assuming similar losses.

There is a large number of literature reviews concerning the development advances of materials that can be used in photoelectrochemical tandem cells. ${ }^{[81-84]}$ Amongst the most promising photoanode materials, one can cite the long-studied $\mathrm{Fe}_{2} \mathrm{O}_{3}$ (stable in a long range of $\mathrm{pH}_{4}-14$ ), ${ }^{[85]}$ $\mathrm{WO}_{3}$ that operates in acidic conditions, ${ }^{[86]}$ and $\mathrm{BiVO}_{4}$ that can be used around neutral $\mathrm{pH} .{ }^{[87]}$ Hematite and tungsten trioxide have been tested in a tandem cell configuration, using a dye-sensitized solar cell instead of a photocathode to promote electrons at an energy sufficient to reduce water on a plat- inum counter electrode but performances were limited by the late photocurrent onset of the photoanode. ${ }^{[88]} \mathrm{BiVO}_{4}$ has also been used in a tandem cell, in combination with a $\mathrm{Cu}_{2} \mathrm{O}$ photocathode ${ }^{[89]}$ or with a $\mathrm{Si}$ solar cell. ${ }^{290]}$ However, these studied evidenced routes for improvement as they showed instability due to detachment of the CoPi catalyst and restricted current originated from bismuth vanadate limited absorption of the solar spectrum.

In terms of photocathode materials, recent studies demonstrated the potential of using $\mathrm{Cu}_{2} \mathrm{O}$, which showed relative stability and current densities of up to $-7.6 \mathrm{~mA}$ $\mathrm{cm}^{-2}$ at $0 \mathrm{~V}$ vs. RHE. ${ }^{[91]} \mathrm{Si}, \mathrm{GaP}$ or $\mathrm{GaAs}$ are other materials vigorously developed in the field but suffer from poor stability in water and require careful protection with overlayers. ${ }^{[92]}$ p-type $\mathrm{GaInP}_{2}$ has also been investigated for water photoreduction and reached a record STH efficiency of $12.4 \%$ in a stand-alone monolithic device, exhibiting however rapid degradation. [93]

Overall while the development of an integrated PEC water splitting device offers a simple way to directly convert our most abundant renewable energy source directly to a chemical storage vector, or solar fuel, considerable efforts are needed to increase the device stability and decrease the cost in order to be economically competitive with traditional solar-to-hydrogen conversion methods (i.e. PV + electrolysis).

\section{Conclusion and Outlook}

Efficient energy storage is required to enable a global energy economy based on renewable energies. For this purpose, chemical storage offers attractive possibilities as it can store the electricity produced from any kind of renewable energy into the bonds of chemical compounds, which themselves can be stored indefinitely and/or transported. Hydrogen and simple carbon-containing compounds (e.g. formic acid, methane, and methanol) are examples of promising energy carriers that can be formed from electricity through electrolysis.

Today, two major technologies lead the market of electrolyzers: the Alkaline and Proton Exchange Membrane types. Alkaline electrolyzers operate in very basic conditions, which offer several advantages, including an inexpensive microporous ceramic diaphragm and electrodes that can be made of relatively simple and cheap materials. Its main drawbacks are the low current density achievable, mostly due to the oxygen diffusion from the anode to the cathode, and significant voltage losses originated from poor oxygen evolution catalysis on the anode. Recent progress however showed that reasonable current can now be achieved at less than $300 \mathrm{mV}$ overpotential using inexpensive materials like steel or NiFe. Unfortunately alkaline electrolyzers are poorly suitable for the dynamic requirements of storing the highly variable renewable energy due to the low partial-load range. In contrast, PEM electrolyzer do not suffer from dynamic load limitations or limited maximum current densities as the proton exchange membrane is a better gas diffusion blocker. The highly acidic environment engendered by the membrane helps the facile catalysis of HER but limits the choice of material for the OER catalysis to expensive and rare metals such as Ir or Ru. This is the main disadvantage for this technology and hindered its expansion on the market. The identification of an inexpensive and stable water oxidation catalyst for use in PEM electrolyzers would be a major breakthrough for these devices.

As an alternative to conventional electrolyzers, research is also focusing on developing systems able to function in natural water - mostly at neutral $\mathrm{pH}$ - and seawater, but demonstrated performances remain quite low in this area. Another direction explored by researchers is the direct conversion of solar energy into a transportable fuel, through photoelectrochemical water splitting. Despite recent progress in the domain, these systems still suffer from poor efficiency and/or poor stability that hinders a large scale application. Further efforts are still needed in order for semiconductor-based devices to compete with already commercialized technologies.

Received: August 21, 2015

[1] M. Densing, S. Hirschberg, H. Turton, in Report prepared for the Group Energy Perspectives and the Swiss Competence Center for Energy Research, 'Supply of Electricity', (SCCER SoE), PSI bericht $\mathrm{N}^{\circ} 14-05,2014$

[2] IEC White Paper, 2015.

[3] P. V. Kamat, J. Phys. Chem. C 2007, 111, 2834.

[4] N. S. Lewis, D. G. Nocera, Proc. Natl. Acad. Sci. U.S.A. 2006, 103, 15729.

[5] M. Beaudin, H. Zareipour, A. Schellenberglabe, W. Rosehart, Energy Sustain. Dev. 2010, 14, 302 .

[6] A. Evans, V. Strezov, T. J. Evans, Renew. Sust. Energ. Rev. 2012, 16, 4141

[7] D. A. Halamay, T. K. A. Brekken, A. Simmons, S. McArthur, IEEE T. Sustain. Energ. 2011, 2, 321.

[8] A. Hauer, J. Quinnell, E. Lavemann, 'Energy Storage Technologies - Characteristics, Comparison, and Synergies', Wiley-VCH Verlag GmbH \& Co., 2003.

[9] L. Bertuccioli, A. Chan, D. Hart, F. Lehner, B. Madden, E. Standen, in 'Development of Water Electrolysis in the European Union', report on behalf of 'Fuel Cells and Hydrogen Joint Undertaking', www.fch.ju.eu, 2014

[10] D. L. Stojić, T. D. Grozdić, B. Umićević, A. D. Maksić, Russ. J. Phys. Chem. A 2008, 82, 1958.

[11] A. Ursua, L. M. Gandia, P. Sanchis, Proc. IEEE 2012, 100, 410 .

[12] M. Carmo, D. L. Fritz, J. Mergel, D. Stolten, Int. J. Hydrogen Energy 2013, 38, 4901. 
[13] M. Felgenhauer, T. Hamacher, Int. J. Hydrogen Energy 2015, 40, 2084.

[14] R. D. L. Smith, M. S. Prévot, R. D. Fagan, Z. Zhang, P. A. Sedach, M. K. J. Siu, S. Trudel, C. P. Berlinguette, Science 2013, 340, 60 .

[15] C. C. L. McCrory, S. Jung, I. M. Ferrer, S. M. Chatman, J. C. Peters, T. F. Jaramillo, J. Am. Chem. Soc. 2015, 137, 4347.

[16] C. C. L. McCrory, S. Jung, J. C. Peters, T. F. Jaramillo, J. Am. Chem. Soc. 2013, 135, 16977.

[17] T. Nakagawa, C. A. Beasley, R. W. Murray, J. Phys. Chem. C 2009, 113, 12958.

[18] M.E. G. Lyons, S. Floquet, PhysChemChemPhys 2011, 13, 5314.

[19] Y. Gorlin, T. F. Jaramillo, J. Am. Chem. Soc. 2010, 132, 13612.

[20] Y. Surendranath, D. K. Bediako, D. G. Nocera, Proc. Natl. Acad. Sci. U.S.A. 2012, 109, 15617.

[21] A. J. Esswein, M. J. McMurdo, P. N. Ross, A. T. Bell, T. D. Tilley, J. Phys. Chem. C 2009, 113, 15068

[22] M. W. Kanan, D. G. Nocera, Science 2008, 321, 1072.

[23] Y. Qiu, L. Xin, W. Li, Langmuir 2014, 30, 7893.

[24] M. W. Louie, A. T. Bell, J. Am. Chem. Soc. 2013, 135, 12329.

[25] L. Trotochaud, S. L. Young, J. K. Ranney, S. W. Boettcher, J. Am. Chem. Soc. 2014, 136, 6744.

[26] X. Lu, C. Zhao, Nat. Commun. 2015, 6, doi:10.1038/ncomms7616.

[27] M. D. Merrill, R. C. Dougherty, J. Phys. Chem. $C$ 2008, 112, 3655

[28] H. Isobe, M. Shoji, K. Koizumi, Y. Kitagawa, S. Yamanaka, S. Kuramitsu, K. Yamaguchi, Polyhedron 2005, 24, 2767.

[29] M. Lundberg, P. E. M. Siegbahn, Chem. Phys. Lett. 2005, 401, 347.

[30] A. Decker, E. I. Solomon, Curr. Opin. Chem. Biol. 2005, 9, 152.

[31] R. H. Holm, P. Kennepohl, E. I. Solomon, Chem. Rev. 1996, 96, 2239.

[32] H. Schafer, S. Sadaf, L. Walder, K. Kuepper, S. Dinklage, J. Wollschlager, L. Schneider, M. Steinhart, J. Hardege, D. Daum, Energy Environ. Sci. 2015, doi: 10.1039/C5EE01601K.

[33] F. Moureaux, P. Stevens, G. Toussaint, M. Chatenet, J. Power Sources 2013, 229, 123.

[34] P. C. Ho, D. A. Palmer, R. H. Wood, J. Phys. Chem. B 2000, 104, 12084.

[35] J. Fischer, H. Hofmann, G. Luft, H. Wendt, AIChE J. 1980, 26, 794.

[36] F. Allebrod, C. Chatzichristodoulou, M. B. Mogensen, J. Power Sources 2013, 229, 22.

[37] S. Rausch, H. Wendt, J. Electrochem. Soc. 1996, 143, 2852.

[38] M. H. Miles, G. Kissel, P. W. T. Lu, S. Srinivasan, J. Electrochem. Soc. 1976, 123, 332.

[39] N. V. Krstajić, B. N. Grgur, N. S. Mladenović, M. V. Vojnović, M. M. Jakšić, Electrochim. Acta 1997, 42, 323.

[40] P. W. T. Lu, S. Srinivasan, J. Electrochem. Soc. 1978, 125, 265.

[41] D. E. Hall, J. Electrochem. Soc. 1985, 132, 41C.

[42] J. Balej, Int. J. Hydrogen Energy 1985, 10, 89.
[43] K. Zeng, D. Zhang, Progr. Energy Combust. Sci. 2010, 36, 307.

[44] D. E. Hall, J. Electrochem. Soc. 1981, 128, 740.

[45] V. Schröder, B. Emonts, H. Janßen, H. P. Schulze, Chem. Eng. Technol. 2004, 27, 847.

[46] A. Goñi-Urtiaga, D. Presvytes, K. Scott, Int. J. Hydrogen Energy 2012, 37, 3358.

[47] S. A. Grigoriev, V. I. Porembskiy, S. V. Korobtsev, V. N. Fateev, F. Auprêtre, P. Millet, Int. J. Hydrogen Energy 2011, 36, 2721.

[48] T. Oi, Y. Sakaki, J. Power Sources 2004, 129, 229

[49] S. A. Grigoriev, V. I. Porembsky, V. N. Fateev, Int. J. Hydrogen Energy 2006, 31, 171.

[50] K. A. Mauritz, R. B. Moore, Chem. Rev. 2004, $104,4535$.

[51] C. Heitner-Wirguin, J. Membr. Sci. 1996, 120, 1 .

[52] K. E. Ayers, E. B. Anderson, C. Capuano, B. Carter, L. Dalton, G. Hanlon, J. Manco, M. Niedzwiecki, ECS Trans. 2010, 33, 3.

[53] B. Hinnemann, P. G. Moses, J. Bonde, K. P. Jørgensen, J. H. Nielsen, S. Horch, I. Chorkendorff, J. K. Nørskov, J. Am. Chem. Soc. 2005, 127, 5308

[54] T. F. Jaramillo, K. P. Jørgensen, J. Bonde, J. H. Nielsen, S. Horch, I. Chorkendorff, Science 2007, 317, 100

[55] M. A. Lukowski, A. S. Daniel, F. Meng, A. Forticaux, L. Li, S. Jin, J. Am. Chem. Soc. 2013, 135, 10274.

[56] D. Voiry, M. Salehi, R. Silva, T. Fujita, M. Chen, T. Asefa, V. B. Shenoy, G. Eda, M. Chhowalla, Nano Lett. 2013, 13, 6222.

[57] C. G. Morales-Guio, X. Hu, Acc. Chem. Res. 2014, 47, 2671.

[58] W.-F. Chen, K. Sasaki, C. Ma, A. I. Frenkel, N. Marinkovic, J. T. Muckerman, Y. Zhu, R. R. Adzic, Angew. Chem. Int. Ed. 2012, 51, 6131.

[59] E. J. Popczun, J. R. McKone, C. G. Read, A. J. Biacchi, A. M. Wiltrout, N. S. Lewis, R. E. Schaak, J. Am. Chem. Soc. 2013, 135, 9267.

[60] L. Feng, H. Vrubel, M. Bensimon, X. Hu, PhysChemChemPhys 2014, 16, 5917.

[61] E. J. Popczun, C. G. Read, C. W. Roske, N. S. Lewis, R. E. Schaak, Angew. Chem. Int. Ed. 2014, 53, 5427

[62] X. Zou, Y. Zhang, Chem. Soc. Rev. 2015, 44, 5148.

[63] C. Iwakura, K. Hirao, H. Tamura, Electrochim. Acta 1977, 22, 329.

[64] T. Reier, M. Oezaslan, P. Strasser, ACS Catalysis 2012, 2, 1765.

[65] R. Kötz, S. Stucki, Electrochim. Acta 1986, 31, 1311.

[66] F. I. Mattos-Costa, P. de Lima-Neto, S. A. S. Machado, L. A. Avaca, Electrochim. Acta 1998, 44,1515 .

[67] A. J. Terezo, J. Bisquert, E. C. Pereira, G. Garcia-Belmonte, J. Electroanal. Chem. 2001, 508, 59.

[68] G. Chen, X. Chen, P. L. Yue, J. Phys. Chem. B 2002, 106, 4364

[69] S. Ardizzone, C. L. Bianchi, G. Cappelletti, M.
Ionita, A. Minguzzi, S. Rondinini, A. Vertova, $J$. Electroanal. Chem. 2006, 589, 160.

[70] J. R. McKone, N. S. Lewis, H. B. Gray, Chem. Mater. 2014, 26, 407.

[71] R. Balaji, B. S. Kannan, J. Lakshmi, N. Senthil, S. Vasudevan, G. Sozhan, A. K. Shukla, S. Ravichandran, Electrochem. Commun. 2009, 11,1700 .

[72] S. M. Ji, H. Jun, J. S. Jang, H. C. Son, P. H. Borse, J. S. Lee, J. Photochem. Photobiol. A 2007, 189, 141

[73] A. Toutianoush, W. Jin, H. Deligöz, B. Tieke, Appl. Surf. Sci. 2005, 246, 437.

[74] K. Izumiya, E. Akiyama, H. Habazaki, N. Kumagai, A. Kawashima, K. Hashimoto, Mater. Trans. JIM 1998, 39, 308.

[75] A. J. Esswein, Y. Surendranath, S. Y. Reece, D. G. Nocera, Energy Environ. Sci. 2011, 4, 499.

[76] M. Dincă, Y. Surendranath, D. G. Nocera, Proc. Natl. Acad. Sci. U.S.A. 2010, 107, 10337.

[77] W. Wang, Q. Zhao, J. Dong, J. Li, Int. J. Hydrogen Energy 2011, 36, 7374

[78] S. Cobo, J. Heidkamp, P.-A. Jacques, J. Fize, V. Fourmond, L. Guetaz, B. Jousselme, V. Ivanova, H. Dau, S. Palacin, M. Fontecave, V. Artero, Nat. Mater. 2012, 11, 802.

[79] M. S. Prévot, K. Sivula, J. Phys. Chem. C 2013, 117,17879

[80] A. Fujishima, K. Honda, Nature 1972, 238, 37.

[81] T. Hisatomi, J. Kubota, K. Domen, Chem. Soc. Rev. 2014, 43, 7520.

[82] M. G. Walter, E. L. Warren, J. R. McKone, S. W. Boettcher, Q. Mi, E. A. Santori, N. S. Lewis, Chem. Rev. 2010, 110, 6446.

[83] F. E. Osterloh, Chem. Soc. Rev. 2013, 42, 2294

[84] Z. Li, W. Luo, M. Zhang, J. Feng, Z. Zou, Energy Environ. Sci. 2013, 6, 347.

[85] K. Sivula, F. Le Formal, M. Grätzel, ChemSusChem 2011, 4, 432.

[86] C. Sartoretti, B. Alexander, R. Solarska, W. Rutkowska, J. Augustynski, R. Cerny, J. Phys. Chem. B 2005, 109, 13685.

[87] K. Sayama, A. Nomura, Z. Zou, R. Abe, Y. Abe, H. Arakawa, Chem. Commun. 2003, 2908.

[88] J. Brillet, J.-H. Yum, M. Cornuz, T. Hisatomi, R. Solarska, J. Augustynski, M. Grätzel, K. Sivula, Nat. Photonics 2012, 6, 824.

[89] P. Bornoz, F. F. Abdi, S. D. Tilley, B. Dam, R. van de Krol, M. Grätzel, K. Sivula, J. Phys. Chem. C 2014, 118, 16959.

[90] F. F. Abdi, L. Han, A. H. M. Smets, M. Zeman, B. Dam, R. van de Krol, Nat. Commun. 2013, 4 , 234.

[91] A. Paracchino, V. Laporte, K. Sivula, M. Grätzel, E. Thimsen, Nat. Mater. 2011, 10, 456.

[92] S. Hu, M. R. Shaner, J. A. Beardslee, M. Lichterman, B. S. Brunschwig, N. S. Lewis, Science 2014, 344, 1005.

[93] O. Khaselev, J. A. Turner, Science 1998, 280, 425 